Maria Miguel Reis

Universidade do Porto

\title{
"O que desaparece? E o que sobra?": leituras intermediais em Pickpocket, de João Miguel Fernandes Jorge
}

Resumo: O presente artigo centra-se no discurso interartístico e no peso da intermedialidade na obra Pickpocket, do autor português João Miguel Fernandes Jorge, pois trata-se de um livro cuja poesia nasce do cinema de Robert Bresson. Num primeiro momento, torna-se fulcral evidenciar a importância da intermedialidade na escrita de Fernandes Jorge, de forma a compreender que tipo de relação o autor estabelece com o cinema. De seguida, partiremos para uma análise do livro que procure salientar e valorizar a sua componente dialogante e, ao mesmo tempo, pensar que tipo de relação a escrita de Fernandes Jorge propõe com o cinema bressoniano.

Palavras-chave: Pickpocket, poesia portuguesa contemporânea, cinema, intermedialidade

Abstract: The present article focuses on the interartistic discourse and in the significance of intermediality in the book Pickpocket, by the author João Miguel Fernandes Jorge, since it's a book whose poetry is born from the cinema of Robert Bresson. Initially, it becomes crucial to emphasize the importance of intermediality in the writing of Fernandes Jorge, to comprehend what type of relationship does the author establishes with the cinema. In turn, we will carry out a book analysis that seeks to underline and cherish its dialoguing component and, at the same time, consider what sort of relationship the writing of Fernandes Jorge proposes with the Bressonian cinema.

Keywords: Pickpocket, contemporary portuguese poetry, cinema, intermediality

\section{A intermedialidade na escrita de João Miguel Fernandes Jorge}

João Miguel Fernandes Jorge é um autor que privilegia muito o diálogo com as várias artes plásticas. ${ }^{1}$ Publicou o seu primeiro livro de poesia em 1971 - Sob Sobre Voz - e, na década de setenta, é ainda de sublinhar a participação do autor na publicação do chamado Cartucho, juntamente com Joaquim Manuel Magalhães, António Franco Alexandre e Helder Moura Pereira. ${ }^{2}$ A deterioração da cultura contemporânea, bem como da natureza, a disforia urbana e o desencanto da vida quotidiana, são algumas das questões transversais na poesia de Fernandes Jorge - muito visíveis, sobretudo, nas primeiras publicações nos anos setenta. 
A afinidade com as artes plásticas depressa se faz sentir na escrita de João Miguel Fernandes Jorge, e podemos afirmar que se trata de um diálogo exaustivo e complexo, pois encontra-se quer em livros de poesia, quer em livros de crítica de arte. ${ }^{3}$ No que diz respeito à poesia, a escrita de Fernandes Jorge encontra-se sempre entre a descrição ecfrástica e a digressão.

O autor privilegia, portanto, um encontro entre o descritivo (écfrase) e o narrativo, de forma a conduzir o leitor quer pelos detalhes da obra artística de onde partiu, quer pela imaginação poética, através de uma fuga desses mesmos detalhes. Vejamos, por exemplo, o poema "Ilha de Capri", da obra Mirleos, que dialoga com a pintura intitulada Ilha de Capri, de Henrique Pousão - reproduzida no fim do livro.

O poema inicia-se com um resgate da natureza, presente na pintura, através da enumeração de sensações provocadas pelos elementos da natureza: "[o] odor o mar os figos/ o sal cortava as ruelas/ o vento sobre os terraços/ entre os ramos dos limoeiros" (Jorge 2015: 98).

Já a figura feminina da pintura surge a meio do poema, e o poeta descreve a mulher como uma espécie de aparição na pintura de Henrique Pousão, isto é, como se ela mesma se tivesse introduzido na pintura: "[...] [a]/ rapariga [...] pisou a tela do moço Henrique/ ficou prisioneira na paisagem no colorido/ no meio do ar" (ibidem). E, por sua vez, no fim do poema, o autor atribui gestos à figura feminina que prolongam essa vontade de vida para lá da imagem da pintura: "e bem antes do sentimento/ à luz da água marinha/ soltou os cabelos do lenço vermelho/ p'la extrema do horizonte” (ibidem). Estamos perante o poder narrativo da escrita de Fernandes Jorge quando dialoga com as artes plásticas: o movimento que o poeta induz nos seus versos para a imagem da pintura forma, no leitor, uma discreta tensão entre visualidade verbal e visualidade gráfica.

Ora, quando o poeta propõe um diálogo com o cinema, podemos afirmar, desde já, que há uma procura por um cinema sensível e despojado; talvez por isso os cineastas de eleição de Fernandes Jorge sejam Robert Bresson, em Pickpocket, e Carl T. Dreyer, em A Palavra - livro que publicou em 2007, dedicado ao cineasta dinamarquês.

No livro A Palavra encontramos um paratexto intitulado "Também em A Palavra o amor se exprime pelo beijo", onde Fernandes Jorge pensa a sua ligação com o cinema, debruçando-se numa profunda reflexão sobre o filme $A$ Palavra. ${ }^{4}$ Este paratexto ajuda-nos a compreender que linhas regem o interesse de Fernandes Jorge pelo cinema. 0 poeta não procura desvendar o poder hermético das imagens em movimento, mas transportar e resgatar esse poder e essa tensão à sua escrita. Nas palavras do autor:

[a]o escolhermos um filme devíamos deixar apenas as imagens e ausentarmo-nos de qualquer palavra ao seu redor. E sendo o filme A Palavra (1954), qualquer cerco de palavras que sobre A Palavra se estenda torna-se facilmente um estorvo. Mas o mecanismo que nos leva à selecção de um filme e à sua eleição entre tantos filmes de que se gostou deve trazer uma explicação, pelo menos no que respeita às motivações da escolha. (Jorge et alii 2007: 43) 
Há, portanto, um conjunto de características, um "mecanismo", que leva à eleição de determinado filme. Ao prosseguirmos com a leitura do paratexto, percebemos a importância das personagens fílmicas para o autor, pois Fernandes Jorge estabelece uma clara diferença entre o ator e a personagem, interessando-se apenas pelas personagens fílmicas, que "[c]omeçam e acabam na singularidade do seu absoluto e na teia de relações que estabelecem e organizam dentro do filme. Têm existência enquanto personagens, enquanto imagens" (ibidem).

Podemos estabelecer um paralelismo entre esta diferença que existe para Fernandes Jorge em relação ao ator e à personagem e a ideia de "modelo" bressoniana, em detrimento do conceito de ator.

A conceção de cinema para Robert Bresson passa por uma recusa do alinhamento do cinema com o teatro, ou seja, há uma rejeição do cinema dito convencional. No livro Notas Sobre o Cinematógrafo, de Robert Bresson, encontramos as reflexões do cineasta sobre as linhas estruturais que definem o cinematógrafo. ${ }^{5}$ Uma dessas linhas é a teoria do modelo e não do ator, de forma a eliminar uma ideia de representação teatral. Segundo o cineasta, os filmes deviam ser executados por modelos, pois

[p]ara Bresson, o cinema, na sua definição comercial corrente, não passa de um veículo para actores profissionais representando uma peça de acordo com as normas teatrais em vigor; ao contrário, o cinematógrafo é o registo de um real não representado, sem actores e sem recorrer a códigos (de dicção, do gesto) vindos do teatro. (Aumont/Marie 2009: 55)

Robert Bresson considera que o cinematógrafo é a arte da verdade, ao passo que o cinema convencional é a arte do falso (cf. Bresson 2000: 59), por isso o cinema bressoniano destaca-se pelo rigor, pela beleza, pela supressão dos gestos ao essencial, pela contenção e pela tensão emocional escondida nos rostos dos modelos - muitas vezes captados em grande plano ou em plano médio. Vejamos a seguinte afirmação do cineasta:

[o] actor projecta-se perante si sob a forma da personagem com quem se quer parecer; empresta-lhe o seu corpo, a sua figura, a sua voz; fá-lo sentar, levantar, andar; impregna-o de sentimentos e de paixões que ele não tem. Esse 'eu' que não é o seu 'eu' é incompatível com o cinematógrafo (Bresson 2000: 65).

Detenhamo-nos na parte final do excerto, pois traduz precisamente essa recusa pela representação e reforça o desejo de verdade no cinema bressoniano: esse 'eu' que não é o seu 'eu'. Pensemos, por exemplo, no rosto e na postura imperturbável e despojada de Jeanne d'Arc, ao longo do filme Procès de Jeanne d'Arc, visto que reforça esse trabalho do "eu" enquanto modelo e não enquanto ator a interpretar a figura história Jeanne d'Arc. Só através desse processo é que Robert Bresson consegue “[...] com palavras históricas 
[...]" encontrar "[...] uma verdade não-histórica" (idem: 112), ou seja, uma verdade íntima em Jeanne d'Arc.

No paratexto em questão, importa destacar, também, a reflexão de Fernandes Jorge sobre a ressurreição final no filme A Palavra:

[a] Inger [...] poderíamos pedir-lhe uma palavra sobre a experiência da morte. Mas o seu olhar, no abandono do beijo, quando a palavra é somente a palavra de um beijo, o seu olhar está ainda perdido. [...]. E o que quererá dizer o seu regresso ao fluxo da vida? Quer somente dizer que é aí, nesse fluxo, que é no viver que está a própria experiência da morte. No entrecruzar da angústia da vida e na angústia da morte está o instinto que nos leva a viver a palavra vida e também a pensar a palavra vida e a temer a palavra morte. (Jorge et alii 2007: 49)

Esta reflexão reforça o fascínio do autor por um cinema que nos faça pensar nos limites entre a vida e a morte e entre o ato e a palavra. Ao mesmo tempo é, também, nos versos mais ecfrásticos do poeta que encontramos os pormenores mais sensíveis que resgata dos filmes; neste caso, encontramos num dos poemas de $A$ Palavra um momento de descrição ecfrástica que remete para uma das sequências mais marcantes do filme de Dreyer, a conversa entre Maren e Johannes:

Maren subiu a uma cadeira, encostou a face ao/ rosto do tio. Guardam o silêncio, o/ afecto do mundo sensível, a interioridade que recorre/ ao caminho marcado pela revelação. As mãos de/ Maren enleiam o pescoço de Johannes/ percorre com ele a luz eterna de um requiem/ suspendem o olhar onde a obscuridade escava, com a/ abelha, o inferno do paraíso. [...] (Jorge et alii 2007: 37) ressuscitasse

Ora, não há uma transposição da conversa entre Maren e Johannes, mas uma descrição ecfrástica da loucura de Johannes a tornar-se sensatez perante a inocência de Maren. Deste modo, é a pureza de Maren que exige a Johannes a ressurreição de Inger, pois onde os restantes familiares veem loucura, a criança vê razão.

Portanto, há duas principais características a destacar na poesia de João Miguel Fernandes Jorge quando dialoga com o cinema. Trata-se de uma poesia de descrições ecfrásticas e transposições narrativas, mas é também uma poesia que promove uma narratividade mais hermética a partir das imagens em movimento.

\section{O diálogo interartístico em Pickpocket}

De forma a problematizar as relações interartísticas presentes no livro Pickpocket, propomos uma leitura da obra enquanto livro de diálogo - conceito que resgatámos do artigo "The livre d'artiste in the Twentieth-Century France", de Elza Adamowicz - e enquanto iconotexto - conceito que retirámos da obra Poetics of the Iconotext, ${ }^{6}$ da professora e investigadora Liliane Louvel. Optámos, também, por resgatar importantes conceitos 
da intermedialidade teorizados por Irina Rajewsky, que nos permitem reforçar a componente dialogante do livro.

Pickpocket é um livro de poesia cujos poemas partem dos filmes de Robert Bresson, mas, além dos poemas, o livro apresenta fotografias dos filmes - cuja responsabilidade pertence a Rita Azevedo Gomes - e um capítulo final intitulado "Pickpocket Rui Chafes", com fotografias de uma exposição do escultor Rui Chafes, dedicada ao cineasta francês. Logo, estamos perante uma obra de diálogo entre três artes: poesia, cinema e escultura. ${ }^{7}$ Esta ligação que o livro abre entre três artes permite-nos introduzir duas importantes reflexões da intermedialidade.

Estamos perante uma obra de combinação intermedial, pois demonstra “[...] the result or the very process of combining at least two conventionally distinct media or medial forms of articulation" (Rajewsky 2005: 52). No entanto, como estamos perante um livro, o cinema e a escultura apenas estão presentes pela via da reprodução e, por isso, torna-se necessário unir o conceito de combinação intermedial com o conceito de referência intermedial. Tal como mostra Rajewsky:

[...] intermedial references, for example references in a literary text to a film through, for instance, the evocation or imitation of certain filmic techniques such as zoom shots, fades, dissolves, and montage editing. Other examples include the so-called musicalization of literature, transposition d'art, ekphrasis, references in film to painting, or in painting to photography, and so forth. (ibidem)

Aliás, o conceito de referência intermedial remete quer para a questão da reprodução, quer para o uso da técnica ecfrástica nos poemas de João Miguel Fernandes Jorge. Podemos afirmar que no livro Pickpocket há uma união entre combinação e referência intermedial.

Ainda dentro das referências intermediais, podemos destacar dois importantes momentos de intertextualidade em Pickpocket. Ora, a alusão à intertextualidade, neste caso em particular, acontece no sentido textual, por isso a relação deixou de ser intermedial e passa a intramedial:

[...] the distinctions between intermedial and intramedial references must not be ignored. These distinctions are due to the fact that intermedial references by definition imply a crossing of media borders, and thus a medial difference (whereas intramedial references by definition remain within a single medium). (Rajewsky 2005: 54)

Referimo-nos aos excertos de outras obras de Fernandes Jorge reproduzidas em Pickpocket: o texto intitulado "Boorz de Gaunes e a rainha Ginevra no Castelo de Palmela”, retirado da obra Uma Paixão Inocente, e o capítulo intitulado "Quatro Castelos de Castelos", que reproduz quatro poemas da obra Castelos de I a XXXV. Ambos os textos se 
encontram depois do capítulo dedicado ao filme Lancelot du Lac. Apercebemo-nos de que há um desejo de prolongamento do mundo medieval do filme de Robert Bresson, que Fernandes Jorge evoca através de referências culturais e jogos temporais.

Ora, isto mostra-nos o quanto o livro estabelece uma interação entre os vários elementos que o compõem. Por isso, o conceito livro de diálogo parece-nos bastante pertinente para pensar Pickpocket, visto que é um conceito que procura uma leitura equitativa das várias artes que podem compor um livro: “[a]rt historian Yves Peyré prefers the term livre de dialogue, which he defines as 'l'égalité de deux expressions dans le surgissement d'une forme nouvelle" (Adamowicz 2009: 190).

Em Pickpocket encontramos este "surgissement d'une forme nouvelle" através da ligação entre os poemas de Fernandes Jorge e o cinema de Robert Bresson e da ligação entre as fotografias das esculturas de Rui Chafes e o cinema bressoniano - em particular o filme Pickpocket - assim como através do diálogo entre as imagens dos filmes espalhadas pelo livro e os versos de Fernandes Jorge.

Aliás, podemos ainda afirmar que a componente dialogante do livro se revela ao leitor mesmo antes da abertura do mesmo; por intermédio do título, que remete para o filme homónimo de 1957 de Robert Bresson - filme que foi considerado por muitos como a obra-prima do cineasta.

O filme Pickpocket centra-se muito na apreensão visível e legível de objetos, por parte do carteirista Michel, no contexto do espaço urbano e privilegiando uma certa deambulação urbana do protagonista, na buca de oportunidades para roubar. Importa salientar que Robert Bresson trabalhou muito a questão do tato nos seus filmes, tal como as situações óticas e sonoras puras, pois "[e]m Bresson os opsignos e os sonsignos são inseparáveis de autênticos tactissignos que regulam talvez as relações entre aqueles (será esta a originalidade dos espaços quaisquer de Bresson)" (Deleuze 2015: 26). ${ }^{8}$

Se o filme Pickpocket evoca, sobretudo, o tato, então podemos pensar no livro Pickpocket enquanto objeto material. A existência do livro enquanto realidade material (cf. Adamowicz 2009: 193) eleva o manuseamento do leitor a uma espécie de relação sensível e intrínseca, da mesma forma que Michel manuseia os pequenos objetos roubados. Através desta relação material entre leitor e livro, abre-se o diálogo entre poesia e cinema, entre filme Pickpocket e livro Pickpocket. O leitor é um leitor carteirista dos diálogos interartísticos do livro.

A convergência de elementos textuais e das artes visuais, no livro, permite que evoquemos o conceito iconotexto. Nas palavras da investigadora Liliane Louvel:

[t]he word 'iconotext' conveys the desire to bring together two irreducible objects and form a new object in a fruitful tension in which each object maintains its specificity. It is therefore a perfect word to designate the ambiguous, aporetic, and in-between object of our analysis. (Louvel 2011: 21)

A analogia entre texto e imagem desencadeará uma tensão na leitura do livro. O uni- 
verso do leitor é invadido por essa tensão entre visualidade verbal e visualidade gráfica: há uma leitura quer dos poemas, quer das imagens.

Vejamos, por exemplo, o poema VI, dos poemas dedicados ao filme Mouchette. Na página ao lado do poema encontramos uma fotografia da cena que encerra o filme: o lago, depois de Mouchette se atirar. Ora, o poema de Fernandes Jorge evoca, precisamente, o momento em que a jovem Mouchette roda sobre si até desaparecer no lago: "e rolou sobre si mesma, voz e corpo, até se tingir de negro o/ que foi raiz branca/ e desapareceu no fundo do horizonte da reduzida lagoa/ ruído surdo no charco da aldeia/ caiu, pedra a ferir o solo da água" (Jorge/Chafes 2009: 28).

Depois de Mouchette desaparecer, o filme encerra com a imagem do lago, que vemos ao lado do poema e que os seguintes versos descrevem: "[a] água ficou densa e sombria. As folhas da árvore/ ficaram brilhantes e negras [...]” (ibidem). Estamos perante uma descrição ecfrástica quer da sequência final do filme, quer da fotografia ao lado do poema. No entanto, o poema não encerra nestes versos, mas nos seguintes: “[...] [e] os homens, quando apanharam/ uma pedra, a pedra ficava nas suas mãos/ negra, um grumo de noite" (ibidem). Este prolongamento do final do filme, nos versos de Fernandes Jorge, desencadeia, no leitor, uma forte tensão entre a fotografia do lago, que o leitor reconhece como a cena final do filme, e os versos de Fernandes Jorge a prolongar esse final. Percebemos, então, que a digressão da poesia do autor ao dialogar com o cinema passa muito por esta ideia de prolongamento do filme - ou seja, é o efeito narrativo que se sobrepõe ao descritivo.

Além desta convergência entre dois sistemas semióticos (texto/imagem), a poesia de Fernandes Jorge também se torna, por si só, um forte elemento de visualidade (verbal). Pensemos no poema "As grandes feridas (Mouchette visita Balthazar)", que celebra o encontro entre duas personagens de filmes distintos de Robert Bresson: a jovem Mouchette - do filme Mouchette - e o burro Balthazar - do filme Au Hasard Balthazar. O percurso de vida quer da jovem Mouchette quer do burro Balthazar é marcado pela solidão, pelo desprezo, pelo abandono e, no final, pela morte.

Mouchette e Balthazar partilham o abandono e a rejeição da sociedade, que no poema está patente num momento de interrogação existencial extremamente íntimo: “[p]or mais miseráveis que sejamos, temos a nossa/ verdade. E para que serve a verdade/ a quem nunca procurou a sua própria verdade? [...]" (idem: 40). A interrogação presente nos versos citados reforça, por um lado, uma das características da poesia de Fernandes Jorge - as questões e os diálogos íntimos do sujeito poético - e, por outro lado, corrobora o encontro e a partilha de emoções entre Mouchette e Balthazar.

No final do poema, Fernandes Jorge une a jovem e o burro através da "borboleta", que "[...] voa e pousa no dorso de Balthazar e logo no/ húmido cabelo da rapariga [...]" (ibidem). A borboleta torna-se símbolo da ligação entre Mouchette e Balthazar e, por sua vez, da eterna peregrinação de ambos.

O leitor rende-se quer à tensão entre texto/imagem que o livro desencadeia, quer à 
visualidade verbal da poesia de João Miguel Fernandes Jorge, que procura sempre evocar o valor hermético das imagens bressonianas. Por isso, os conceitos livro de diálogo e iconotexto revelam-se essenciais para compreender que o livro Pickpocket procura uma tensão artística entre poesia e cinema e abre diversas possibilidades de leitura dessa tensão.

\section{Procès de Jeanne d'Arc e "Diário de Lançarot do Lago pelos dias de Agosto de 2008"}

O conceito de écfrase tem sido alvo de inúmeras reflexões ao longo das décadas, desde propostas que procuram restringir o conceito a conceções que procuram alargá-lo. Podemos resgatar, então, a definição proposta pelo teórico James A. W. Heffernan, para pensar o diálogo da poesia de João Miguel Fernandes Jorge com o cinema. Nas palavras de Heffernan:

[i]f ekphrasis is to be defined as a mode, the definition must be sharp enough to identify a certain kind of literature and yet also elastic enough to reach from classicism to postmodernism, from Homer to Ashbery. What I propose is a definition simple in form but complex in its implications: ekphrasis is the verbal representation of graphic representation. (Heffernan 1991: 299)

Se nos detivermos na principal ideia formulada por Heffernan, ekphrasis is the verbal representation of graphic representation, então podemos afirmar que a poesia de Fernandes Jorge se encontra entre a representação verbal e a digressão. Aliás, nas palavras do poeta: "[n]ão tenho alma de cinéfilo. O filme para mim foi sempre um universo de passagens bruscas, mesmo escarpadas, que vão de um estado de total adesão a um imediato esquecimento" (Jorge et alii 2007: 43). No entanto, e parafraseando Fernandes Jorge, podemos afirmar que é este modo singular de se relacionar com o cinema (cf. Jorge et alii 2007: 43) que o torna, sem dúvida, um poeta com alma de cinéfilo, pois é na interseção entre a adesão e o esquecimento que Fernandes Jorge dá ao leitor os versos mais belos do cinema bressoniano.

O filme Procès de Jeanne d'Arc - talvez um dos mais belos filmes de Robert Bresson - mostra-nos a capacidade única do cineasta em comover o espetador através da contenção emocional. Ou seja, a emoção de Jeanne não é dada a ver, está contida na postura e no rosto da jovem. E é através deste exercício de retenção íntima das emoções, a que Robert Bresson submete os seus modelos, que os filmes bressonianos se transformam em filmes extremamente emocionais.

Ora, é precisamente num dos poemas dedicados ao filme Procès de Jeanne d'Arc, "O Manto Branco", que Fernandes Jorge escreve um dos mais sublimes momentos de descrição ecfrástica:

"[s] egura uma pequena cruz,/ dois estreitos ramos de um qualquer arbusto com/ rudeza cruzados. $\mathrm{O}$ andar para o martírio do fogo, desamparados/ passos, pisam de modo cego a pedra 
do chão./ Impassível, sem um ritus de temor aceita grosseiro cinto à/ volta do corpo,/ [...]/ A grande cruz aproxima-se [...]/ quando uma derradeira palavra é dita 'Jesus'. (Jorge/Chafes 2009: 50)
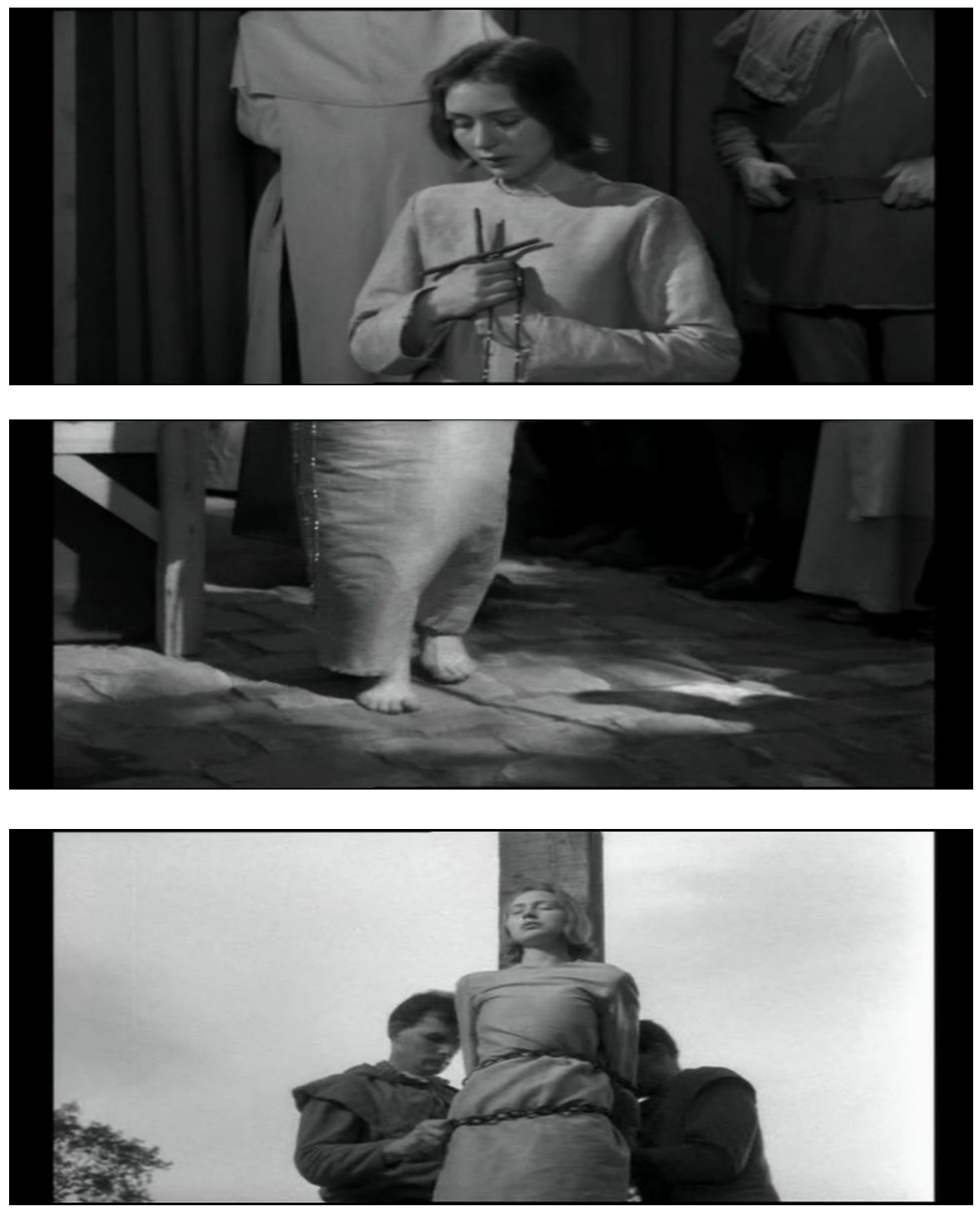

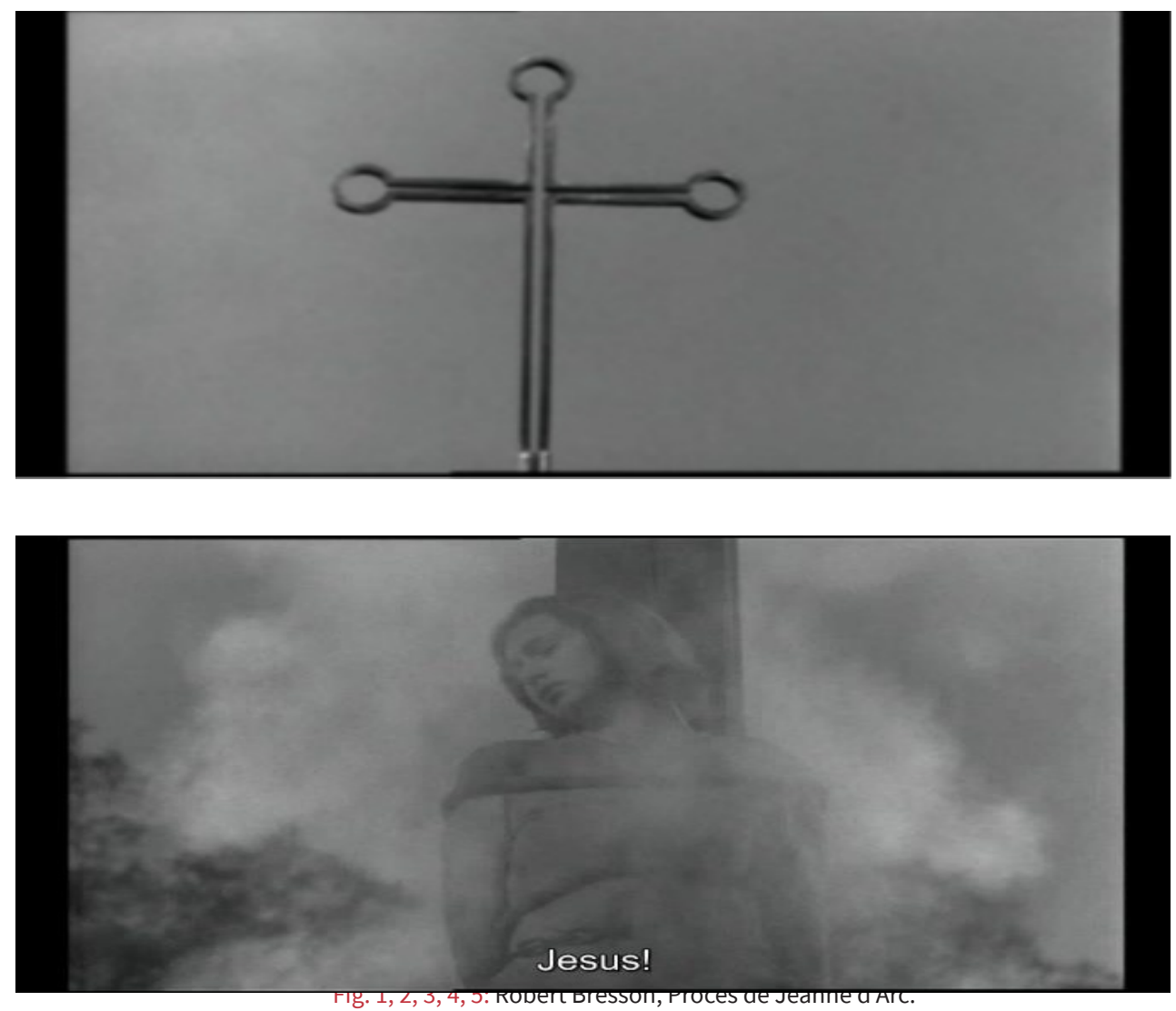

Os versos ecfrásticos de João Miguel Fernandes Jorge acompanham o desejo de comoção pela via da contenção, de Robert Bresson, pois é na postura "impassível" de Jeanne d'Arc, sem temor ao enfrentar o auto de fé, e na crença intrínseca nas vozes que a acompanham, que o espetador e, por sua vez, o leitor, se depara com um dos momentos mais comoventes do cinema bressoniano.

O poeta privilegia, também, um tom reflexivo em relação ao destino de Jeanne d'Arc e ao processo de condenação, numa espécie de enaltecimento da figura de Jeanne e de eternização. No penúltimo poema que dedica ao filme de Robert Bresson, intitulado "O que desaparece? E o que sobra?", encontramos o seguinte verso: “[a]s vozes íntimas trouxeram-lhe a magnanimidade da coragem" (Jorge/Chafes 2009: 51). Este verso traduz, precisamente, a verdade íntima da Jeanne de Robert Bresson e podemos estabelecer um paralelismo entre este verso e uma frase proferida por Jeanne d'Arc na sala de interrogatório: "Je dirai la verité. Mais je ne dirai pas tout".

Depois dos poemas dedicados ao filme Procès de Jeanne d'Arc, o leitor encontra um capítulo intitulado “Diário de Lançarot do Lago pelos dias de Agosto do ano de 2008”, que 
remete para o filme Lancelot du Lac. Ora, é nestes poemas, tal como o título do capítulo indica, que encontramos o grande desejo de narrar de Fernandes Jorge. O universo das lendas arturianas do filme de Robert Bresson encontra-se submerso em versos que privilegiam uma forte digressão lírica e evocam, em diversos momentos, resquícios da lírica medieval trovadoresca. No entanto, o que nos parece uma forte dispersão de imagens, nestes poemas de Lancelot du Lac, depressa se revela uma união, cujo fio condutor é, justamente, uma ideia e uma sensação de demanda inspirada nos cavaleiros das lendas arturianas.

Vejamos, por exemplo, os seguintes versos extraídos de diferentes poemas: "[o]nde estais Senhora minha/ pois na torre coberta pela neve do inverno já não esperas?" (Jorge/ Chafes 2009: 69); "Persival cativou a donzela que lhe semelhou tam/fremosa que nunca outra em beldade chegasse/ ora era assim coitado damor" (idem: 72); "[e] eu entam era cavaleiro/ assi como vos agora sodes/ e andava com eles/ floresta e noite se estreitavam" (idem: 78).

Repare-se no forte arcaísmo lexical dos versos de Fernandes Jorge e na presença da temática amorosa, como a "coita d'amor", própria das cantigas de amor. Aliás, podemos referir o poema "5 de agosto, terça-feira" que apresenta um sujeito poético feminino, uma das principais características das cantigas de amigo, a lamentar os seus infortúnios amorosos: "[a]mor ele sofrerá eu cuidarei em/ Camaalot por meu amigo que não/ é trovador/ dom Lançarot é cavaleiro/ cruel fugitivo vejo seu corpo" (idem: 63).

Por sua vez, saliente-se o poema "29 de agosto, sexta-feira", que nos fala de "[c]omo o donzel perdeu seus homens e andou/ errado" (idem: 85), ou seja, remete-nos para as cantigas de amor, onde o cavaleiro declara o seu amor a uma senhora e a sua servidão para com esse amor.

Neste poema em particular, o donzel sofre por uma donzela que se encontra imersa num "[...] obscuro presságio [...]” (idem: 85), isto é, num destino fatal do qual não conseguiu escapar. A donzela é vista como uma figura mais etérea e inalcançável do que terrena. A associação da pele da donzela ao luar reforça muito essa presença mais celestial do que material: "[...] [q]ue vos direi: a sua pele era cor/ do luar/ [...] a cor do luar sobre a laguna" (ibidem).

O poema revela-nos que o "eu" lírico é prisioneiro das memórias da sua donzela, por isso o tom do poema é extremamente pesaroso: "a sua cor, cor do luar/ era também a dos peixes mortos pela madrugada a tempestade/ deixa poisar à porta/ da minha casa/ à beira de água" (ibidem). Há uma passividade no "eu" lírico em relação ao sofrimento e à evocação da donzela: o "eu" aceita este destino errante e o poema, assim, encerra da mesma maneira com que se iniciou, isto é, a evocação da donzela e o desalento do sujeito poético,

[q]ue vos direi: Aquela donzela nunca afastava/ um passo que fosse/ a sua presença, sombra de sombra./ Era sensível ao obscuro presságio/ à presença da morte que ronda sempre/ em 
torno dos homens./ Que vos direi: Aquela donzela, no muro do seu nome/ minha vida secreta. (Jorge/Chafes 2009: 85)

Deste modo, os poemas de Procès de Jeanne d’Arc e de "Diário de Lançarot do Lago pelos dias de Agosto de 2008”, permitem-nos afirmar que a écfrase, em João Miguel Fernandes Jorge, além de permitir ao poeta reproduzir na sua escrita os pormenores mais delicados dos filmes, é também um forte dispositivo de narratividade - ou seja, uma narratividade entre o filme e a deriva desse mesmo filme.

A leitura de Pickpocket apresenta, portanto, momentos ecfrásticos em convergência com uma errância poética, forçando o leitor a atravessar sensações de perda do filme que, a qualquer momento, volta a emergir em discretas referências. Assim, o leitor perceciona esse confronto entre aproximação e distanciamento - que nunca se revela um abandono, na sua totalidade, dos filmes - e a tensão entre poesia e cinema aumenta à medida que a leitura progride.

Por um lado, uma análise da intermedialidade na escrita de João Miguel Fernandes Jorge permite-nos compreender como as artes visuais assumem um papel central na escrita do autor, bem como o fascínio por um cinema de imagens rigorosas e sensíveis. Neste tópico, a leitura do paratexto "Também em A Palavra o amor se exprime pelo beijo", da obra A Palavra, revelou-se de extrema importância, pois conduz o leitor pelas linhas que regem o interesse de Fernandes Jorge pelo cinema.

Por outro lado, é através de uma leitura intermedial e interartística que ficamos a perceber a ligação e a interação entre as várias artes atuantes no livro. Esta ligação que a intermedialidade permite construir suprime qualquer ideia de dispersão que, à primeira vista, a obra poderia suscitar. Podemos afirmar que há uma redescoberta, por parte do leitor, do universo cinematográfico de Robert Bresson, através dos versos de Fernandes Jorge, ou seja, não estamos apenas perante um livro de poesia sobre cinema, mas perante um livro de questionamentos artísticos e de tensão entre poesia e cinema.

Em suma, "O que desaparece? E o que sobra?", questiona um dos poemas finais dedicados a Procès de Jeanne d'Arc, que nos faz pensar, precisamente, neste encontro entre poesia e cinema, a escrita de João Miguel Fernandes Jorge promove um encontro entre a memória e o esquecimento do filme, que faz emergir uma escrita entre a descrição e a digressão. Ora, a procura quase obsessiva de Robert Bresson pelo despojamento, pela depuração, pela beleza e pelo rigor, contamina a escrita poética de Fernandes Jorge: há um resgate das temáticas mais sensíveis do cineasta para os poemas. 


\section{NOTAS}

${ }^{1}$ A reflexão do presente artigo tem origem na pesquisa desenvolvida pela autora no âmbito da sua dissertação de Mestrado em Estudos Literários, Culturais e Interartes, intitulada Acontecimentos de Leitura: Pickpocket de João Miguel Fernandes Jorge e a cinematografia de Robert Bresson.

${ }^{2}$ No ano de 1976, no contexto do pós 25 de abril, e em plena discussão das teorias do pós-modernismo, sai a publicação coletiva Cartucho. Por um lado, a originalidade da publicação estava no seu formato manual, isto é, os poemas encontravam-se soltos e amarrotados dentro de um cartucho de mercearia. Por outro lado, os poemas apresentavam temáticas relacionadas com o quotidiano e a sociedade contemporânea, através de um forte trabalho na linguagem e um rigor verbal que conduzia ao despojamento e, por sua vez, ao efeito de coloquialidade. $\mathrm{O}$ tom provocatório da publicação acabou por definir um momento de rutura nas linhas da poesia portuguesa contemporânea.

${ }^{3} \mathrm{O}$ autor apresenta um profundo trabalho reflexivo sobre arte, pois além de ter sido docente na área da Estética é, frequentemente, curador de exposições artísticas. Podemos destacar as obras Processo em arte, Longe do Pintor da Linha Rubra, A Gravata Ensanguentada e A Flor da Rosa.

${ }^{4}$ João Miguel Fernandes Jorge escreve, também, no livro A Palavra, um outro importante paratexto que se intitula "A luz nórdica em pintores dinamarqueses", onde estabelece uma ligação entre os filmes de Dreyer e uma determinada pintura dinamarquesa. Além da tematização poética há um interesse teórico-crítico, por parte de Fernandes Jorge, em relação ao cinema.

${ }^{5}$ Neste contexto, a palavra cinematógrafo remete para a conceção de cinema segundo Robert Bresson: "[f]ilme de cinematógrafo, onde a expressão se obtém por relações de imagens e de sons - e não por uma mímica, gestos e entoações de voz (de actores ou de não-actores). Que não analisa nem explica. Que recompõe" (Bresson 2000: 20).

${ }^{6} \mathrm{~A}$ versão consultada desta obra é uma versão digital, por isso o número de páginas não corresponde à versão impressa.

${ }^{7}$ Apesar de a fotografia ser, também, um dispositivo atuante no livro Pickpocket, optámos por não abordar esta questão e centrámo-nos, sobretudo, na ligação entre poesia e cinema.

${ }^{8} \mathrm{O}$ teórico Gilles Deleuze expõe estas reflexões na obra $A$ imagem-tempo Cinema 2. A ascensão de situações óticas e sonoras no cinema, distintas de situações sensorio-motoras, emergiu sobretudo no neorrealismo italiano do pós segunda guerra mundial - “[é] um cinema de vidente e já não um cinema de acção” (Deleuze 2015: 9). Segundo o teórico, a imagem-ação (situação sensorio-motora), característica do cinema tradicional, sofre uma crise que fará emergir as situações puramente óticas e sonoras (imagem-tempo) do cinema moderno: a personagem vê-se a si própria em situações de limite e deixa de haver o efeito ação-reação. 


\section{BIBLIOFILMOWEBGRAFIA}

Adamowicz, Elza (2009), “État présent The livre d'artist in the Twentieth-Century France", French Studies, $\mathrm{n}^{\circ} 2,189-198$, <https://academic.oup.com/fs/article/63/2/189/524221> (último acesso em 25/3/2020).

Aumont, Jaques/ Michel Marie (2009), Dicionário teórico e crítico de cinema, Lisboa, Edições Texto \& Grafia.

Bresson, Robert (2000), Notas Sobre o Cinematógrafo, Lisboa, Porto Editora.

-- (dvd), Pickpocket: 1957, p/b, 75'.

-- (dvd), Procès de Jeanne d'Arc: 1962, p/b, 65'.

-- (dvd), Au Hasard Balthazar: 1966, p/b, 95'.

-- (dvd), Mouchette: 1967, p/b, 78'.

-- (dvd), Lancelot du Lac: 1974, cor, 85'.

Deleuze, Gilles (2015), A imagem-tempo Cinema 2, Lisboa, Documenta.

Dreyer, Carl Theodor (dvd), Ordet: 1955, p/b, 126'.

Heffernan, James A. W. (1991), "Ekphrasis and Representation", New Literary History, $\mathrm{n}^{\circ} 2$, 297-316, <https://www.jstor.org/stable/pdf/469040.pdf> (último acesso em 25/3/2020).

Jorge, João Miguel Fernandes (1989), Uma Paixão Inocente, Lisboa, Cotovia.

--(2004), Castelos de I a XXXV, Lisboa, Averno.

-- (2007), A Palavra, Lisboa, Cinemateca Portuguesa.

--(2009), Pickpocket, Lisboa, Cinemateca Portuguesa.

--(2015), Mirleos, Relógio D’Água.

Louvel, Liliane (2011), Poetics of the Iconotext, Burlington, Ashgate Publishing Company (edição digital).

Rajewsky, Irina O. (2005), “Intermediality, Intertextuality and Remediation: A literary perspective on intermediality”, Intermédialités, n²6, 43-46, <https://www.erudit.org/en/ journals/im/2005-n6-im1814727/1005505ar/> (último acesso em 25/3/2020). 